---مجلة علوم الرافدين، المجلد 27، العدد 4/ عدد خاص بالمؤتمر العلمي الثالث لعلوم الحياة، ص297-311، 2018-

الفعالية التثبيةية لمعقدات الكويلت الثنائية المثتقة من الهيدرازيدات الحامضية في نمو جرثومة Staphylococcus aureus

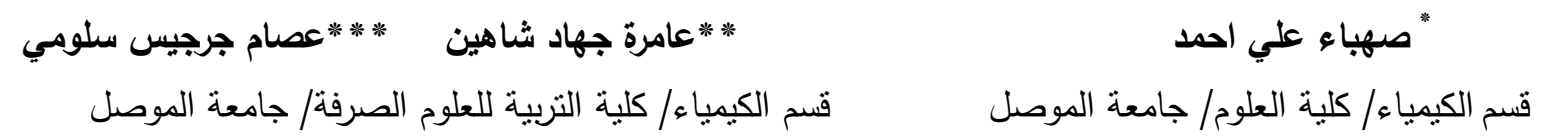

E-mail:*** Sallomi@yahoo.com **a.inorganic@yahoo.com

*Sahbaa.ali@gmail.com

$$
\text { (أستلم 2018/ }
$$

\begin{abstract}
الملخص
تم في هذا البحث تحضير وتشخيص ودراسة لعدد من المعقدات الجديدة للكوبلت (II) مع ثناث ليكاندات من نوع قواعد

شيف ثنائية الهيدرازيد وهي: ثنائي بنزونيليدين مالونويل ثنائي هيدرازيد (L و وثنائي بنزونيليدين فثالوليل ثنائي هيدرازيد $\left(\mathrm{L}_{2} \mathrm{H}_{4}\right)$ الاطياف الاكترونية، القياسات المغناطيسية وأطياف الأشعة تحت الحمراء واستتادا إلى ذلك فان التئين الليكاندات الثثلاثة تعطي معقدات في الوسط المتعادل ايونية موجبة لها الصيغة العامة M(LH4)]

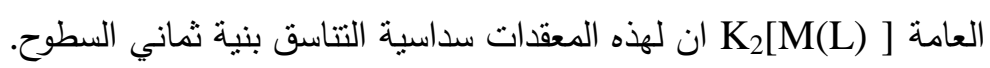

وكذلك تضمن البحث دراسة بايولوجية لليكاندات ومعقداتها ضد نوع من البكتريا المرضية (الموجبة لصبغة كنة كرام) وهي

Staphylococcus aureus كما تم تحديد التركيز الأدنى المنبط (MIC) لبعض المعقدات فضلاً عن دراسة نأثير هذه المعقدات على المستوى الجزيئي من حيث المحتوى ألبروتيني الكلي لجرثومة Staphylococcus aureus.
\end{abstract}

Staphylococcus الكلمات الدالة: حامض الهيدرازيد، معقدات قواعد شيف، معقدات الكوبلت الثنائية، عوامل مضادة لبكتريا aureus

\title{
Inhibition Activity of Cobalt (II) Complexes Derived from Acid Hydrazide on Growth of Staphylococcus aureus and its Protein Contents
}

\author{
Sahbaa A. Ahmed \\ Department of Chemistry/ College of Science/ University of Mosul \\ Amira J. Al-Shaheen \\ Issam J. Sallomi \\ Department of Chemistry/ College of Education Pure Science/ University of Mosul
}

\begin{abstract}
The work reported deals with the preparation characterization and studies of a number of new complexes of cobalt (II). with three ligands type of Schiff base dihydrazide the ligands are: dibenzoinlidenemalonoyldihydrazide $\left(\mathrm{L}_{1} \mathrm{H}_{4}\right)$, dibenzoinlidenesuccinyldihydrazide $\left(\mathrm{L}_{2} \mathrm{H}_{4}\right)$ and dibenzoinlidenephthalolyldihydrazide $\left(\mathrm{L}_{3} \mathrm{H}_{4}\right)$. The prepared complexes have been characterized the different studies by molar conductance, electronic spectra, and magnetic susceptibility
\end{abstract}




$$
\text { صهباء علي احمد وآخرون }
$$

measurements and infrared spectra. The different studies suggest that in neutral medium the ligands formed cationic complexes of the type $\left[\mathrm{M}\left(\mathrm{LH}_{4}\right)\right] \mathrm{X}_{2}$. While in a basic medium anionic complexes of the general formula $\mathrm{K}_{2}[\mathrm{M}(\mathrm{L})]$ were obtained the complexes formed are also hexacoordinated with octahedral structures. Further study was conducted to have an idea about the biological activity of the ligands and their complexes against species of gram positive: Staphylococcus aureus It was found that these complexes have certain degree of reactivity, which they are more active in comparison to their ligands. Also the Minimum Inhibitory Concentration (MIC) was determined for some complexes. In addition to that, the effect of these compounds at the molecular level was studied by measuring the changes of total protein for Staphylococcus aureus bacteria.

Keywords: acid hydrazide, Schiff base complexes, cobalt (II) complexes, antibacterial agent Staphylococcus aureus, total protein.

\section{المقدمة}

تتميز الهيدرازيدات الحامضية بامتلاكها الصيغة العامة R-CO-NH-NH2 وهي ذات فعالية بايولوجية واسعة النطاق (Sallomi et al., 2011 ; Al-Shaheen et al., 2012)

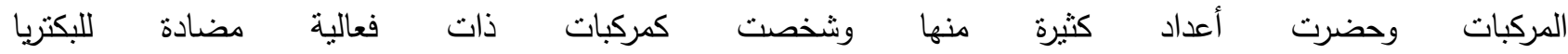
كما ان لمعقداتها فعالية ضد عدد من أنواع البكتريا المعروفة وهي (Savanini et al., 2002 ; Al-Shaheen et al., 2013) (Chohan et al., 2000; Pseudomonas aeruginosa, Escherichia coli gtaphylococcus aureus Bernhardt et al., 2008) (آيزونيكونتيل هيدرازيد) كمادة كيموعلاجية فعالة (Bavin et al., 1952) (Isoniazid) (Mycobacterium tuberculosis) (Muhi-Eldeen et al., 1991 ; المرضية او خلايا الأحياء المسببة للمرض، إذ يكون للمعقد بحالته الأيونية أو المتعادلة Al- Shaheen, 2011) تتطلب دراسة الفعالية الحياتية للمركبات المحضرة تحديد أنواع مختارة من البكتريا إذ يحتمل أن يكون تأثنير هذه المراه المركبات

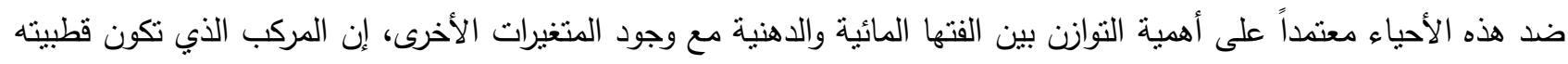
واطئة والصفة التساهمية في أواصره عالية نكون الفته الدهنية أعلى من الفته المائي (Schraufstatter,1950) وقد وجد أندئ أن

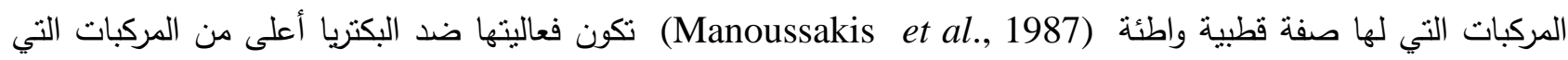
تكون قطبيتها عالية، ويعزى ذلك إلى قابلية النوع الأول اختراق جدار الخلية الدهني والتأثنر في مكوناتها ولاسيما البكتريا الموجبة لصبغة كرام لقد تم التركيز في البحث الحالي على استخدام العناصر الانتقالية التي أثتبت معقداتها نأثيرات حياتية مختلفة ومهمة ويمكن ان يعزى سبب فعالية هذه المركبات إلى عدة أسباب(Laurence and Bennette, 1990) منها ان لمحاليل هذه المركبات القابلية على إذابة جدار الخلية الخارجي مما بؤدي إلى نضوح سوائل هذه الخلية وموتها وتعد المركبات التي تؤثر على لهى الجدار الخلوي من أكثر العوامل انتقائية وذات مؤشر علاجي عالٍ وذلك بسبب اختلاف التركيب بين الجدار الخلوي للمضيف والخلايا الجرثومية.

ولإمكانية إحلال احد العناصر الفلزية الموجودة في الخلية بسبب الفته نحو المشتق محل الفلز ضمن تركيب المعقد وبذلك

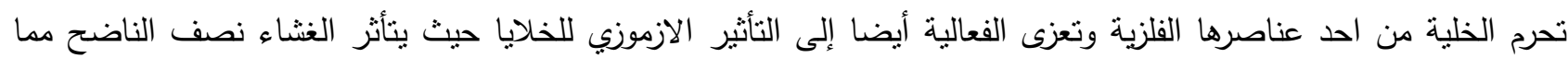
يوقف نشاط الغشاء السايتوبلازمي ومن ثم يعرقل مرور المركبات الضرورية للايض (Richards et al.,1993) وقد يسبب وجود المجاميع الالكيلية ضمن نركيب الليكاند الفعال حياتيا الى تكوين معقدات مع العناصر الموجودة في جسم الخلية منل 
التي تحتاجها الخلية البكتيرية ويؤدي فقدان هذه العناصر إلى موت الخلية. إن اتحاد $\mathrm{Cu}^{2+}$ ، Co $\mathrm{Co}^{2+}$ ، $\mathrm{Fe}^{2+}$ ، $\mathrm{Zn}^{2+}$ ، $\mathrm{Mg}^{2+}$ الليكاندات او معقداتها مع المركبات الحيوية المسؤولة عن سبر العمليات الحياتية داخل الخلية يؤثز في سير هذه العمليات، فيثلاً

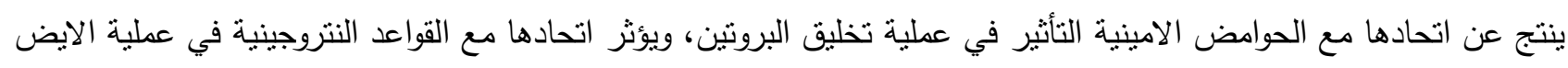
هذه المركبات والمركبات

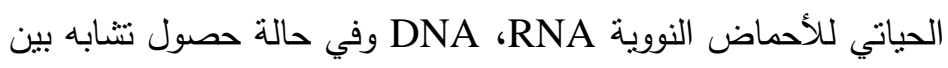

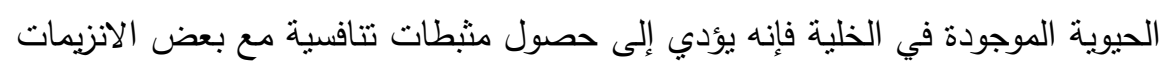
(Marshall and Piddock 1993) درست فعالية هذه المركبات ضد نوع من البكتريا الموجبة لصبغة كرام ومنها المكورات العنقودية الذهبية Staphylococcus aureus من الجراثيم الموجبة لصبغة كرام تتنظم بشكل عناقيد العنب واسعة الانتشار في الطبيعة اذ نوجد عموما على سطح الجلا والأغثية

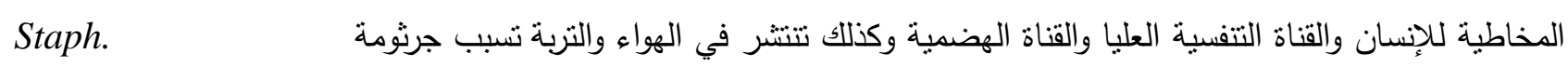
aureus (Novak

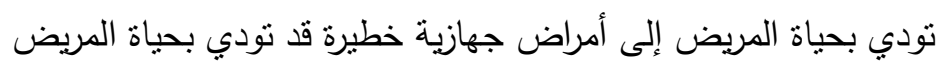
.et al., 2000 ; Prescott and Harley, 1996)

\section{المواد وطرائق العمل}

اولاً: الجزء الكيميائي

أ- القياسات القيزياوية والأجهزة المستخدمة: الجيائ

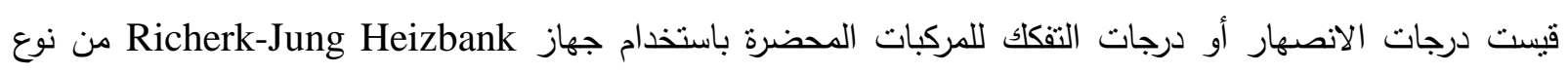
Conductivity Meter-Model وجهاز Wlectrothermal WME

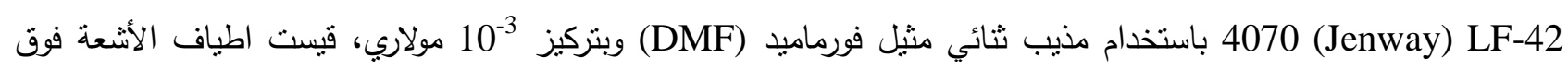
البنفسجية والمرئية بجهاز (U.V.) من نوع (Shimadzu U.V.-210) واستعمل المذيب (DMF) واستخدمت خلية من الكوارتز ذات قطر 1 سم وبمدى (200-1000) نانوميتر سجلت قياسات طيف الأشعة تحت الحمراء لليكاندات والمعقدات المحضرة اذ واذ عملت على شكل أقراص بمادة KBr وبجهاز Pye-Unicam-SP-1100 Infrared Spectrophotometer في المنطقة المحصورة ما بين (400-4000) سم -1استخدم جهاز IR 300 Spectrophotometer Thermomattson قيست الحساسية المغناطيسية للمعقدات المحضرة باستخدام طريقة فراداي اما تحليل العناصر فعينت كمية الكوبلت باستخدام طرائق ترسيبية (Vogel, 1971). ب- الطرائق التحضيرية: اتبعت الطريقة الموجودة في الأدبيات (Baker et al., 1950) في تحضير الليكاندات المشتقة من الهيدرازيدات الحامضية مع البنزوين وتحضير معقدات هذه الليكاندات مع أملاح الكوبلت حيث حضرت الليكاندات (15،

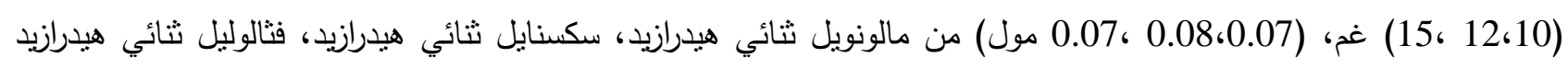

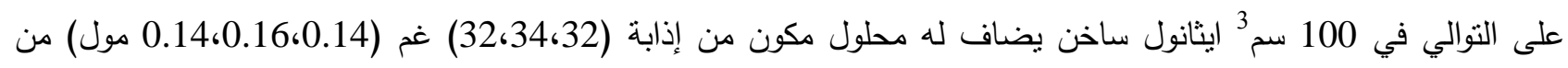
البنزوين في 150 سم ايثانول، بعد مزج المحلولين تجري عملية التصعيد الحراري لمدة ست ساعات على الأقل ثم يبرد المحلول

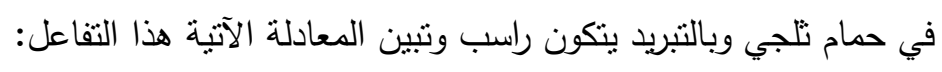




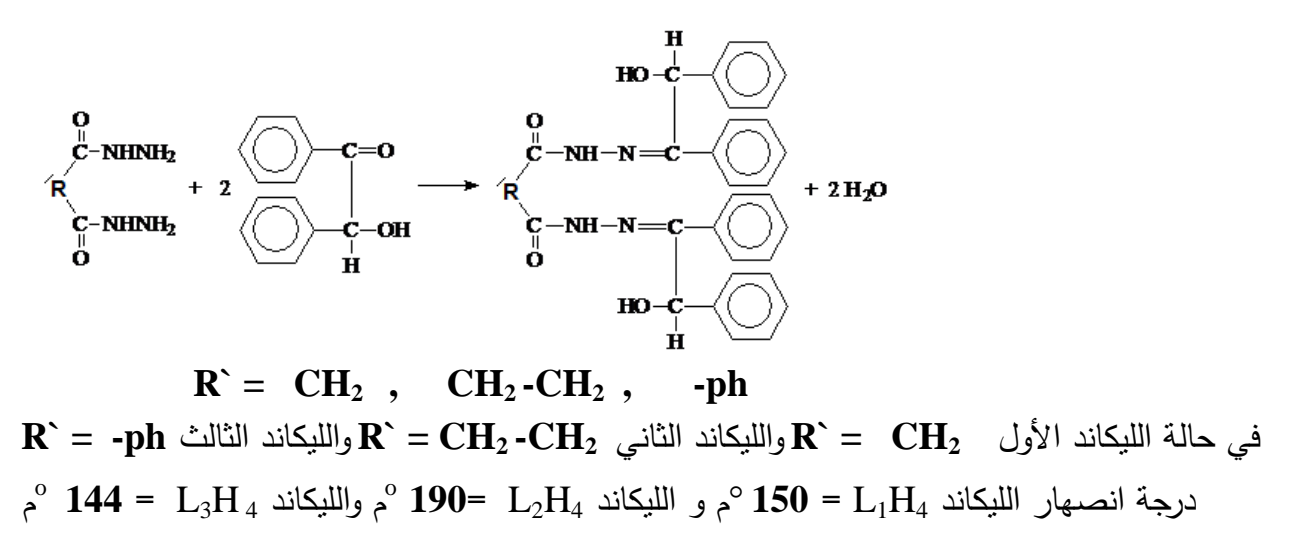

تحضير المعقدات: حضرت معقدات الكوبلت(II) باستخدام أملاح الكلوريد والنترات للفلز في:

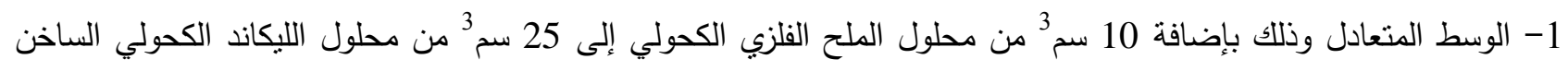

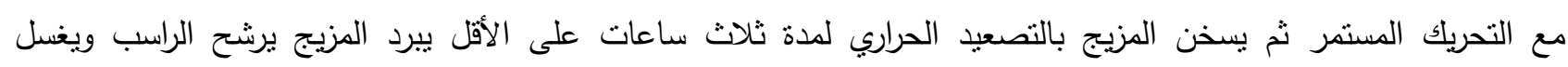
بالايثانول البارد ويجفف. 2- الوسط القاعدي وذلك بإضافة 10سم3 من محلول الملح الفلزي الكحولي الى 25 سم3 من محلول الليكاند الكحولي الساخن مع التحريك المستمر ومن ثم إضافة محلول هيدروكسيد البوتاسيوم الكحولي (1 مولاري) إلى أن تصبح الدالة الحامضية قرابة (9-10)

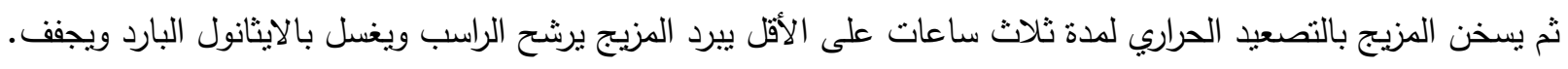
ثانيا :الاراسة البيولوجية: استخدمت الطرائق الآتية: 1. طريقة اختبار الحساسية (طريقة الانتشار بالأقراص): اتبعت طريقة (Bauer et al., 1966) وهي طريقة انتشار المادة في الاكار (Agar) من خلال قرص حاوٍ على هذه المادة اذ ينقع كل قرص في محلول المركب تحت الدراسة وبنركيز 200ملغم/مل في مذيب ثثائي مثيل سلفوكسايد (DMSO) وبعد ذلك تختبر فعالية المركبات المحضرة واستخدمت هذه الطريقة لسهولتها وللاقتصاد في الوسط الغذائي المستعمل (Nawas et al., 1994) اذ نقلت (4-5) مستعمرات نقية للبكتريا Staphylococcus aureus

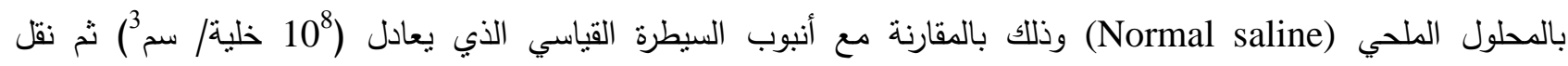

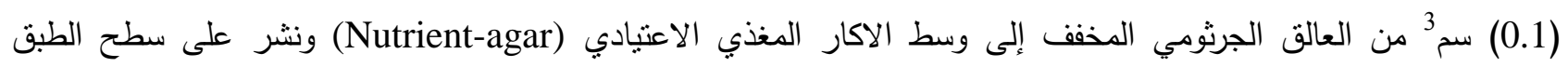
باستعمال مسحة قطنية معقمة (Sterile cotton swabs) نركت الأطباق بدرجة حرارة (37 من م) لمدة (30) دقيقة لحصول عملية Whatmann No. التشرب. ولأجل دراسة نأثير المركبات المضرة على نمو الجرثومة فقد تم تحضير أقراص من ورق الترشيحة

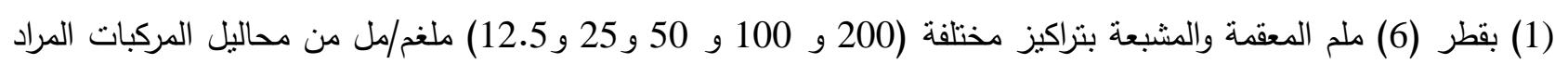

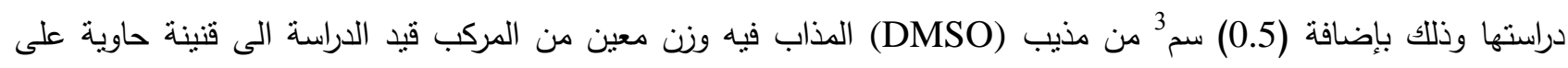

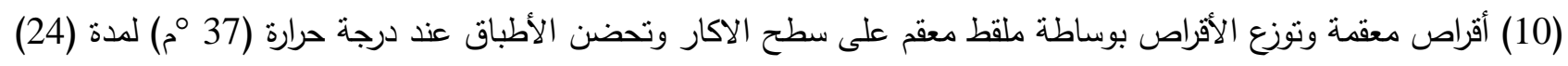
ساعة. واعتمدت فترة التحضين المتلى للنمو بالاعنماد على منحني النمو القياسي. استخدمت طريقة (Prescott et al., 1996)

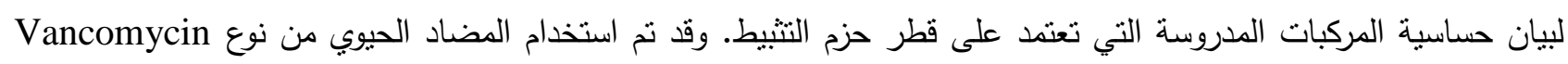
للجراثيم الموجبة لصبغة كرام أي أنها استخدمت لجرثومة Staphylococcus aureus بالاعنماد على ما يستخدم في مختبر الصحة العامة والمعتمد على فحوصات منظمة الصحة العالمية (Vandepitte et al., 1991).

\section{2. تحديد التركيز الأدنى المثبط: Determination of Minimum Inhibitory Concentration (MIC)}


حددت هذه التراكيز من خلال تحضير المحاليل المخففة بتراكيز مختلفة اذ طبقت هذه الطريقة على بعض المعقدات التي أبرزت قدرة تثبيطية جيدة، اذ حضرت المحاليل المخففة بالتراكيز الآتية: (200 و 100 و 50 و 25 و 12.5) ملغم/ مل وحدد هليز

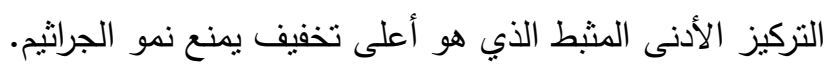

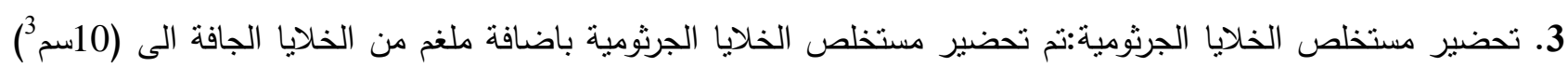

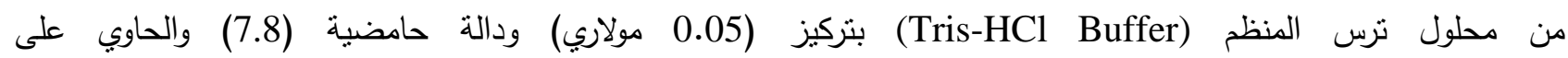
هنتركيز (1 ملي مول) لإزالة المواد اللاخلوية، ثم حطمت الخلايا الجرثومية (EDTA) Ethylenediaminetetraacetic acid باستخدام جهاز الترددات فوق الصوتية (Ultrasound) بتسليط (24000) ذبذبة/ ثانية لمدة (30 ثانية). كررت هذه العملية أربع

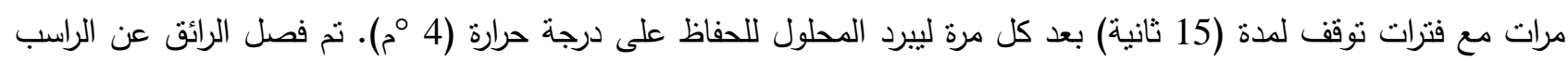

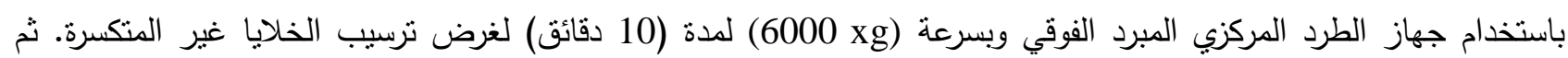
أضيف ( 0.1 سم³) من العالق الجرثومي الى (5 سم²) من وسط المرق المغذي (Nutrient broth) وحضن الوسط بدرجة حرارة

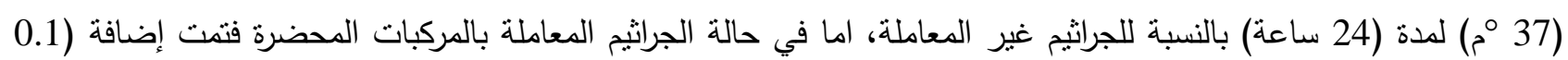

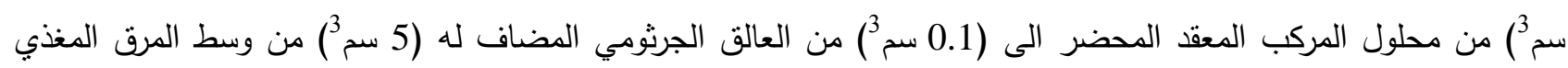
وحضن الوسط بدرجة حرارة (37 ○م) ولمدة (24 ساعة). بعد ذلك تم فصل الرائق عن الراسب باستخدام جهاز الطرد المركزي (Heraeus-Christ, GmbH, D3360, West

المبرد الفوقي (Ultracentrifuge) من نوعن حرون

.Germany) 4. تقدير كميـة البروتين: استخدمت في هذه الدراسـة طريقة لاوري (Lowry et al., 1951) لتحديد كمية البروتين للجراثيم المعاملة بالمركبات المحضرة وغير المعاملة.

\section{النتائج وإلمناقشة}

درست الليكاندات والمعقدات الناتجة بالطرائق الكيمياوية والفيزياوية والطيفية وكما هو موضح في الآتي:

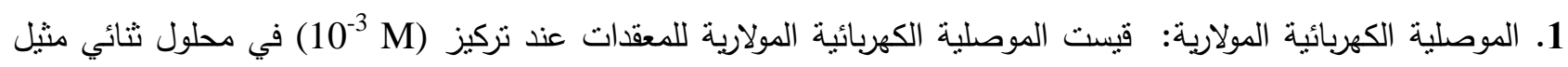
فورماميد بعد السماح للمحلول أن يكون في حالة توازن حراري عند درجة حرارة الغرفة وقد تبين من نتائج الموصلية الكهربائية أن المعقدات المحضرة في المحيط المتعادل نكون الكتروليتية في المحلول بنسبة 1:2 في حين تكون المعقدات المحضرة في المحيط

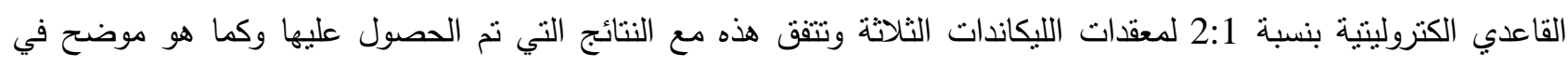

الجدول (1).

2. القياسات المغناطيسية: قيست العزوم المغناطيسية لمعقدات الكوبلت (Figgs and Lewis, 1960) (II) وأعطت المعقدات (1- 9) المبينة في الجدول (1) قيماً للعزوم المغناطيسية إذ تشير هذه القيم إلى معقدات الكوبلت الثنائي الموجب ذات بنية ثماني

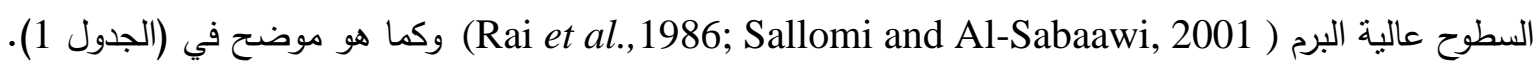
3. الأطياف الاككترونية: قيست الاطياف الاككترونية للمعقدات المحضرة باستخدام مذيب ثنائي مثنل فورماميد (DMF) وقد اعطت المعقدات المحضرة اطياف (d-d) فضلاً عن أطياف انتقال الثحنة لمعدات الكوبلت المحضرة في كل من الوسطين

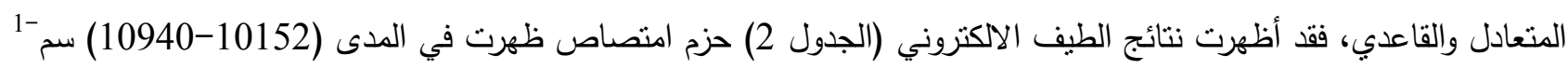

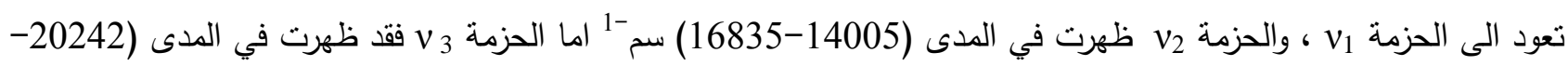

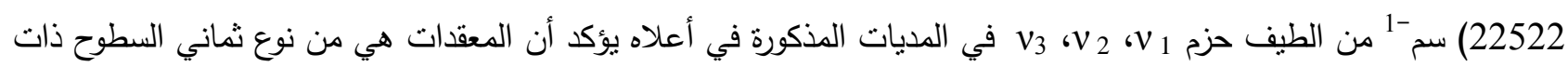

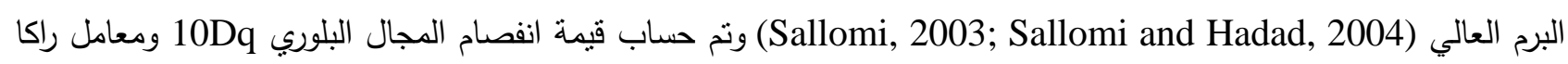

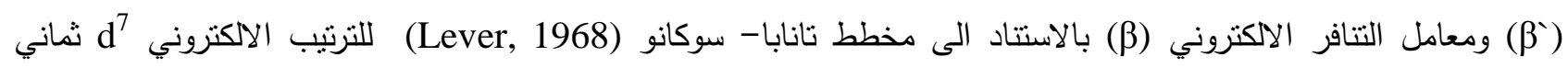




$$
\text { صهباء علي احمد وآخرون }
$$

السطوح وقد لوحظ ان قيمة 10Dq المحسوبة مساوية لقيمة الاتثقال 1 و وتتير قيمة م الواطئة الى زيادة الصفة التساهمية بين

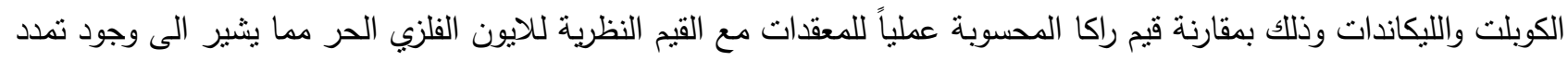

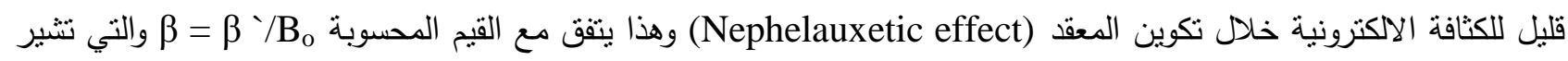

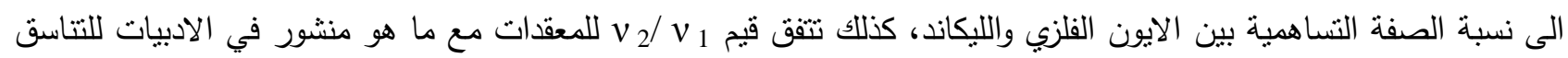

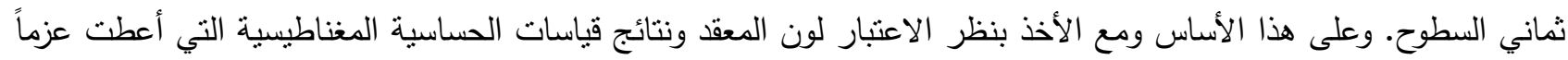
تتزاوح ما بين (4.91-3.11) ويمكن اقتراح تتاسق ثماني السطوح حول ايون الكوبلت (II) وتطابق هذه الصيغ نتائج التحليل بطيف الأشعة تحت الحمراء كما هو مبين في (الجدول 3) التي بينت ارتباط الفلز بالليكاند عن طريق ذرات الأوكسجين والنتروجين.

الجدول 1: النتائج التحليلية وعدد من الخصائص الفيزيائية لمعقدات

\begin{tabular}{|c|c|c|c|c|c|c|}
\hline $\begin{array}{c}\mu_{\text {eff }} \\
\text { B.M. }\end{array}$ & | النسبة المئوية للفلز & درجة الانصهار & $\begin{array}{c}\text { التوصيلية اوم }{ }^{-2}{ }^{2}{ }^{2}{ }^{2}{ }^{-1}{ }^{2} \\
\Lambda_{M} \text { DMF }\end{array}$ & اللون & الصيغة & رقم \\
\hline 3.99 & $\begin{array}{c}9.07 \\
(8.75)\end{array}$ & 220 & 164 & اخضر غامق & {$\left[\mathrm{Co}\left(\mathrm{L}_{1} \mathrm{H}_{4}\right)\right] \mathrm{Cl}_{2}$} & 1 \\
\hline 4.10 & $\begin{array}{c}9.03 \\
(8.51)\end{array}$ & 206 & 157 & بني & $\mathrm{K}_{2}\left[\mathrm{Co}\left(\mathrm{L}_{1}\right)\right]$ & 2 \\
\hline 3.99 & $\begin{array}{c}8.39 \\
(8.15)\end{array}$ & 253 & 155 & بني غامق & {$\left[\mathrm{Co}\left(\mathrm{L}_{1} \mathrm{H}_{4}\right)\right]\left(\mathrm{NO}_{3}\right)_{2}$} & 3 \\
\hline 3.92 & $\begin{array}{c}8.88 \\
(8.75)\end{array}$ & 250 & 160 & اخضر غامق & {$\left[\mathrm{Co}\left(\mathrm{L}_{2} \mathrm{H}_{4}\right)\right] \mathrm{Cl}_{2}$} & 4 \\
\hline 3.96 & $\begin{array}{c}8.84 \\
(8.63)\end{array}$ & 271 & 152 & اخضر غامق & $\mathrm{K}_{2}\left[\mathrm{Co}\left(\mathrm{L}_{2}\right)\right]$ & 5 \\
\hline 4.02 & $\begin{array}{c}8.22 \\
(8.15)\end{array}$ & 264 & 170 & بني غامق & {$\left[\mathrm{Co}\left(\mathrm{L}_{2} \mathrm{H}_{4}\right)\right]\left(\mathrm{NO}_{3}\right)_{2}$} & 6 \\
\hline 3.91 & $\begin{array}{c}8.28 \\
(8.27)\end{array}$ & 266 & 163 & اصفر & {$\left[\mathrm{Co}\left(\mathrm{L}_{3} \mathrm{H}_{4}\right)\right] \mathrm{Cl}_{2}$} & 7 \\
\hline 4.04 & $\begin{array}{c}8.25 \\
(8.15)\end{array}$ & 200 & 149 & بني فاتح & $\mathrm{K}_{2}\left[\mathrm{Co}\left(\mathrm{L}_{3}\right)\right]$ & 8 \\
\hline 4.11 & $\begin{array}{c}7.71 \\
(7.55)\end{array}$ & 224 & 141 & بيجي & {$\left[\mathrm{Co}\left(\mathrm{L}_{3} \mathrm{H}_{4}\right)\right]\left(\mathrm{NO}_{3}\right)_{2}$} & 9 \\
\hline
\end{tabular}


الجدول 2: الأطياف الاكترونية لمعقدات الكويلت (II) باستخدام مذيب (DMF) سم-1)

\begin{tabular}{|c|c|c|c|c|c|c|c|c|c|c|}
\hline رقمق & الصيغة & $v_{1}$ & $v_{2}$ & $v_{3}$ & C.T & $v_{2} / v_{1}$ & $\beta$ & $\beta$ & $10 \mathrm{Dq}$ & البنية \\
\hline 1 & {$\left[\mathrm{Co}\left(\mathrm{L}_{1} \mathrm{H}_{4}\right)\right] \mathrm{Cl}_{2}$} & 10373 & 16835 & 21498 & 29498 & 1.62296 & 484.46 & 0.4989 & 10373 & $\begin{array}{l}\mathrm{OC} \\
\mathrm{T}\end{array}$ \\
\hline 2 & $\mathrm{~K}_{2}\left[\mathrm{Co}\left(\mathrm{L}_{1}\right)\right]$ & 10482 & 15772 & 20242 & 29585 & 1.50467 & 304.53 & 0.3136 & 10482 & $\begin{array}{l}\mathrm{OC} \\
\mathrm{T} \\
\end{array}$ \\
\hline 3 & {$\left[\mathrm{Co}\left(\mathrm{L}_{1} \mathrm{H}_{4}\right)\right]\left(\mathrm{NO}_{3}\right)_{2}$} & 10706 & 14619 & 21097 & 28653 & 1.36549 & 239.86 & 0.2470 & 10706 & $\begin{array}{l}\mathrm{OC} \\
\mathrm{T}\end{array}$ \\
\hline 4 & {$\left[\mathrm{Co}\left(\mathrm{L}_{2} \mathrm{H}_{4}\right)\right] \mathrm{Cl}_{2}$} & 10940 & 16286 & 21551 & 29940 & 1.48866 & 334.46 & 0.3444 & 10940 & $\begin{array}{l}\mathrm{OC} \\
\mathrm{T}\end{array}$ \\
\hline 5 & $\mathrm{~K}_{2}\left[\mathrm{Co}\left(\mathrm{L}_{2}\right)\right]$ & 10482 & 14409 & 22026 & 29940 & 1.37464 & 332.60 & 0.3425 & 10482 & $\begin{array}{l}\mathrm{OC} \\
\mathrm{T}\end{array}$ \\
\hline 6 & {$\left[\mathrm{Co}\left(\mathrm{L}_{2} \mathrm{H}_{4}\right)\right]\left(\mathrm{NO}_{3}\right)_{2}$} & 10593 & 14005 & 21097 & 29940 & 1.32209 & 221.53 & 0.2281 & 10593 & $\begin{array}{l}\mathrm{OC} \\
\mathrm{T} \\
\end{array}$ \\
\hline 7 & {$\left[\mathrm{Co}\left(\mathrm{L}_{3} \mathrm{H}_{4}\right)\right] \mathrm{Cl}_{2}$} & 10152 & 15290 & 22026 & 30864 & 1.50610 & 457.33 & 0.4709 & 10152 & $\begin{array}{l}\mathrm{OC} \\
\mathrm{T} \\
\end{array}$ \\
\hline 8 & $\mathrm{~K}_{2}\left[\mathrm{Co}\left(\mathrm{L}_{3}\right)\right]$ & 10940 & 15408 & 22522 & 30864 & 1.40840 & 340.66 & 0.3508 & 10940 & $\begin{array}{l}\mathrm{OC} \\
\mathrm{T} \\
\end{array}$ \\
\hline 9 & {$\left[\mathrm{Co}\left(\mathrm{L}_{3} \mathrm{H}_{4}\right)\right]\left(\mathrm{NO}_{3}\right)_{2}$} & 10706 & 14836 & 21097 & 31152 & 1.38576 & 254.33 & 0.2619 & 10706 & $\begin{array}{l}\mathrm{OC} \\
\mathrm{T}\end{array}$ \\
\hline
\end{tabular}

- OCT: Octahedral

4. أطياف الأشعة تحت الحمراء: نم تدقيق أهم حزم الليكاندات الحرة ومعقداتها المحضرة لمعرفة وجود التتاسق مع الفلز ومنها مجموعة الازوميثاين C=N حيث ظهر التردد لليكاندات الثلاث بحدود (1615-1630) سم -1 وعند التتاسق مع الفلز إزاحة هذه

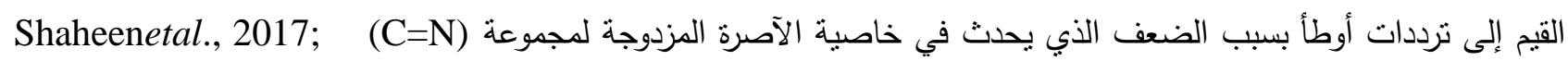

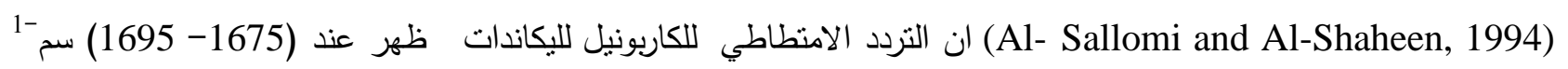
والتردد الواطئ يعزى (Nakamoto, 1978) الى الاصرة الهيدروجينية بين مجموعة الكينون ومجاميع الهيدروكسيل OH في الليكاندات (Sankar et al.,2010; Sallomi and Hadad, 2004). وظهرت حزمة تردد مجموعة الكاربونيل للمعقدات في الوسط المتعادل عند ترددات اوطأ بمقدار (10-25) سم -1 ويعود ذلك الى تناسق ذرة الاوكسجين الكاربونيلية مع

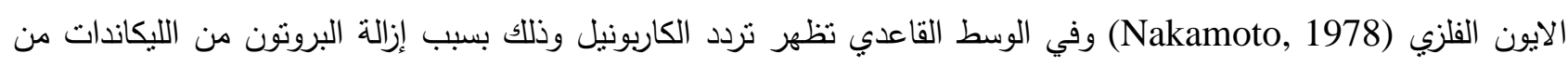

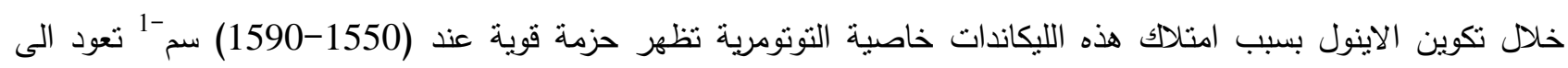

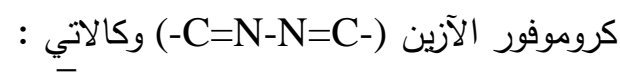

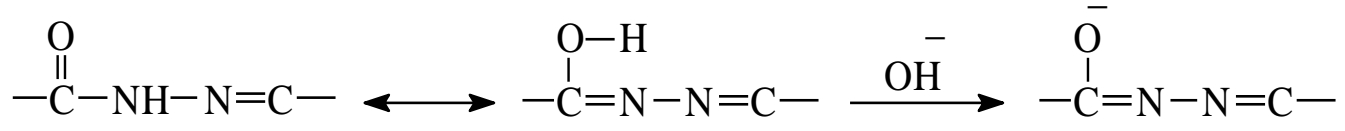

وهكذا تتناسق الليكاندات في الوسط القاعدي بشكلها الايوني السالب مع الأيونات الفلزية عن طريق ذرة الاوكسجين الاينولي والتزدد الامنطاطي لآصرة C-O (Sathyadevi et al., 2012; Al-Shaheen et al., 2012) (1200-1220) سم -1 وقد أزيح هذا التردد إلى قيم اوطأ مما يدل على تتاسق الايونات الفلزية مع ذرة الاوكسجين الاينولية وكما

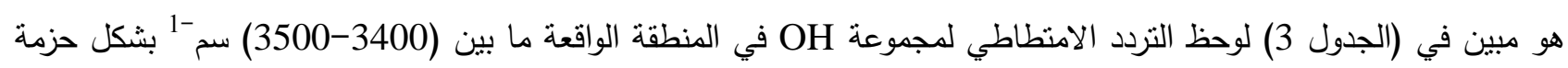

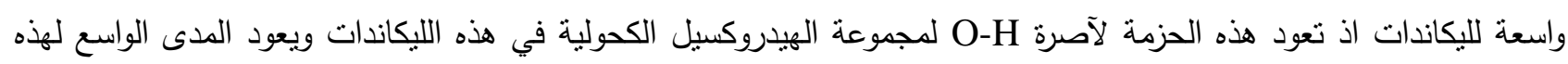


الحزمة الى وجود الأواصر الهيدروجينية كما ظهرت الحزمة(1255-1275) سم -1 فإنها تعود الى نزدد الاتحناء لمجموعة OH الكحولية ان التردد الامتطاطي لمجموعة NH ظهرت في المنطقة الواقعة ما بين (3200-N300) سم -1275 لليكاندات الثلاثة أما

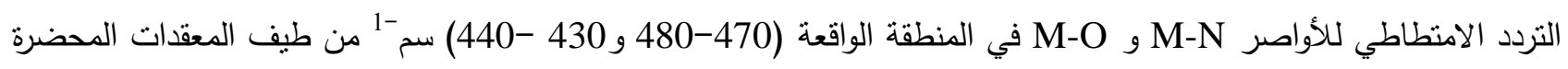
Alagesan et al., 2013) (625-570) سم '1 والتي تعود إلى ايونات

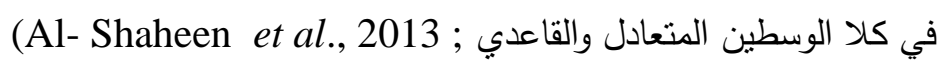

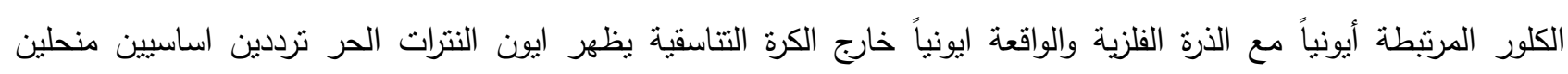

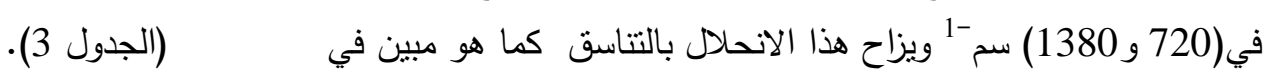

الجدول 3: طائفة من الحزم المهمة في طيف الأثعة تحت الحمراء لليكاند الثثلاثة ومعقداتهم في الوسطين المتعادل والقاعدي

\begin{tabular}{|c|c|c|c|c|c|c|c|c|c|c|c|c|}
\hline $\begin{array}{l}\mathrm{V} \mathrm{NO}_{3} \\
\text { ionic }\end{array}$ & \begin{tabular}{|c|}
$\begin{array}{cl}\mathrm{Cl} \\
\text { ionic }\end{array}$ \\
\end{tabular} & v M-N & V M-O & $\mathbf{v ~ N}-\mathbf{N}$ & $v \mathrm{C}=\mathrm{N}-\mathrm{N}=\mathrm{C}$ & v C-O & $\delta \mathrm{OH}$ & $v \mathrm{C}=\mathrm{N}$ & $v \mathrm{C}=\mathrm{O}$ & $v$ NH & v OH & المركب \\
\hline- & - & - & - & 1035 & - & 1200 & 1255 & 1630 & 1685 & 3250 & 3400 & $\mathrm{~L}_{1} \mathrm{H}_{4}$ \\
\hline $\begin{array}{l}6720 \\
1380\end{array}$ & 580 & 480 & 440 & 1055 & - & 1180 & 1225 & 1610 & 1675 & 3245 & 3300 & 1 \\
\hline- & - & 470 & 430 & 1050 & 1550 & 1175 & - & 1595 & - & - & - & 2 \\
\hline $\begin{array}{l}، 720 \\
1380\end{array}$ & 585 & 480 & 440 & 1050 & - & 1180 & 1235 & 1595 & 1675 & 3245 & 3280 & 3 \\
\hline- & - & - & - & 1030 & - & 1220 & 1275 & 1615 & 1695 & 3300 & 3410 & $\mathrm{~L}_{2} \mathrm{H}_{4}$ \\
\hline $\begin{array}{l}، 720 \\
1380\end{array}$ & 600 & 475 & 430 & 1040 & - & 1200 & 1255 & 1575 & 1685 & 3300 & 3290 & 4 \\
\hline- & - & 480 & 440 & 1040 & 1570 & 1200 & - & 1585 & - & - & - & 5 \\
\hline $\begin{array}{r}.720 \\
1380 \\
\end{array}$ & 595 & 480 & 435 & 1050 & - & 1190 & 1255 & 1585 & 1675 & 3290 & 3300 & 6 \\
\hline- & - & - & - & 1020 & - & 1205 & 1275 & 1625 & 1675 & 3200 & 3500 & $\mathrm{~L}_{3} \mathrm{H}_{4}$ \\
\hline $\begin{array}{r}.720 \\
1380 \\
\end{array}$ & 575 & 480 & 440 & 1045 & - & 1180 & 1255 & 1600 & 1665 & 3200 & 3390 & 7 \\
\hline- & - & 480 & 440 & 1040 & 1560 & 1185 & - & 1585 & - & - & - & 8 \\
\hline $\begin{array}{l}6720 \\
1380\end{array}$ & 605 & 470 & 435 & 1050 & - & 1185 & 1250 & 1605 & 1650 & 3195 & 3400 & 9 \\
\hline
\end{tabular}

نتائج الفعالية البايولوجية للمركبات المحضرة ضد البكتريا:

في هذه الدراسة نم اختبار الفعالية البيولوجية لليكاندات والمعقدات المحضرة جميعها في الوسطين المتعادل والقاعدي كمضادات للبكتريا وباستخدام المضاد الحيوي Vancomycin نتير النتائج المبينة في (الجدول 4) أن الليكاند (Lئنة فعالية تثبيطية قليلة جداً ضد بكتريا S. aureus وكما هو مبين في الصورة (1)، اما معقداته فقد تميزت المعقدات (1، 2، 3)

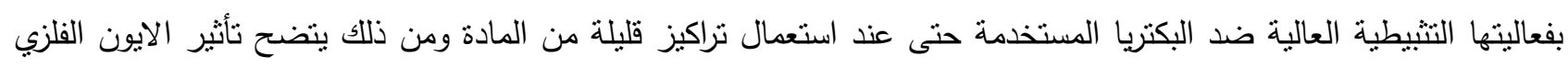

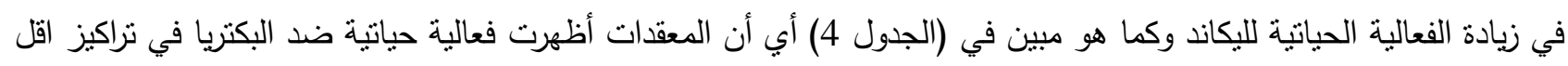
من التركيز الأدنى المطلوب للعقار القياسي وكما هو مبين في الصورة (2) إن إدخال الفلز في تركيز الليكاند (Lئ طبيعة تأثيره الحياتي، اذ يلاحظ تأثنير قليل لليكاند ضد البكتريا حنى ضمن التراكيز العالية. وأظهرت معقدات هذا الليكاند فعالية 


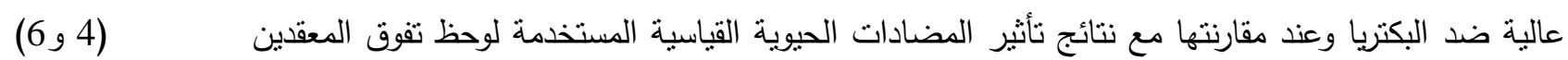
عليها بفعالية تثبيطية عالية جداً من خلال قطر دائرة التثبيط لها وللمضاد الحيوي وكما هو مبين في (الجدول 4) والصورة (2)،

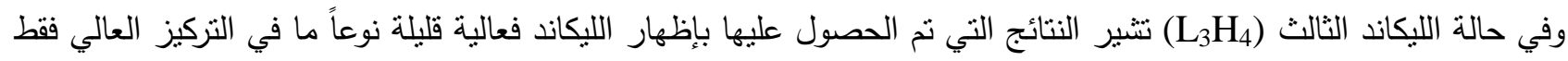
ولم تظهر أية فعالية تجاه البكتريا في جميع التراكيز الاخرى وكما هو مبين في (الجدول 4) والصورة المرفقة (1) أما معقداته المحضرة في الوسطين المتعادل والقاعدي فقد اختبرت فعاليتها ضد البكتريا واظهر المعقدان (7 و 8) فعالية تتبيطية عالية ضد فئ البكتريا حتى عند استعمال نراكيز قليلة من المادة وقد لوحظ ان قطر دائرة التثبيط للمعقدين اكبر من قطر دائرة التثبيط لمضادات .S. aureus

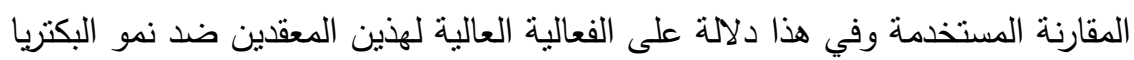
تتصف معقدات قواعد شيف بكونها ذات فعالية حياتية عالية ضد البكتريا الموجبة وكما هو مبين في (الجدول 4) اذ تكون

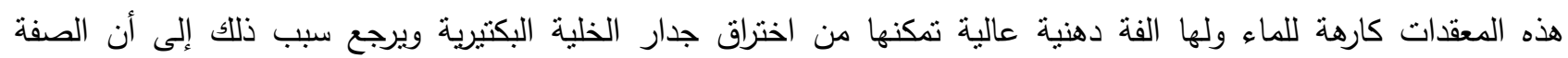
التساهية في أواصر هذه المعقدات أعلى من الصفة القطبية (Prescott et al., 1996) وقد بينت حسابات معامل التتافر الالكتروني م للمعقدات (1-9) (الجدول 2) ان الصفة التناهمية في أواصر تللك المعقدات أعلى من الصفة القطبية اذ نراوحت

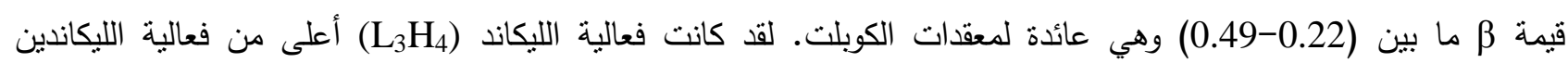
ضد البكتريا وقد يرجع سبب ذلك الى ان الليكاند ( L $\left.\mathrm{L}_{2} \mathrm{H}_{4} \mathrm{~L}_{3} \mathrm{~L}_{1} \mathrm{H}_{4}\right)$

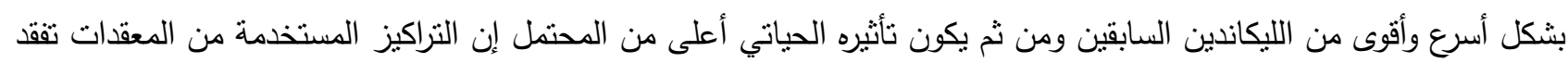

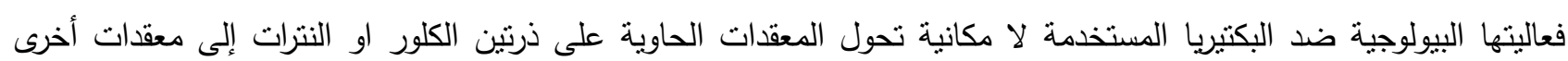
حاويه على ذرتين او ذرة واحدة بفعل الانزيمات الخلوية التي تفرزها البكتيريا لمقاومة الفعل الكيمائي للمعقد وضمن التراكيز

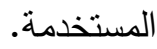

الجدول 4: تأثير الليكاند $\left(\mathrm{L}_{1} \mathrm{H}_{4}-\mathrm{L}_{2} \mathrm{H}_{4}-\mathrm{L}_{3} \mathrm{H}_{4}\right)$ ومعقداتهم على بكتريا S. aureus الموجبة لصبغة كرام

\begin{tabular}{|c|r|c|}
\hline $\begin{array}{c}\text { Comp. } \\
\text { No. }\end{array}$ & \multirow{2}{*}{ Compound } & Gr $^{+}$ \\
\cline { 3 - 3 } & & S. aureus \\
\hline Ligand & $\mathrm{L}_{1} \mathrm{H}_{4}$ & 4 \\
\hline 1 & {$\left[\mathrm{Co}\left(\mathrm{L}_{1} \mathrm{H}_{4}\right)\right] \mathrm{Cl}_{2}$} & 18 \\
\hline 2 & $\mathrm{~K}_{2}\left[\mathrm{Co}\left(\mathrm{L}_{1}\right)\right]$ & 17 \\
\hline 3 & {$\left[\mathrm{Co}\left(\mathrm{L}_{1} \mathrm{H}_{4}\right)\right]\left(\mathrm{NO}_{3}\right)_{2}$} & 17 \\
\hline Vancomycin & $\mathrm{Control}$ & 14 \\
\hline Ligand & $\mathrm{L}_{2} \mathrm{H}_{4}$ & 4 \\
\hline 4 & {$\left[\mathrm{Co}\left(\mathrm{L}_{2} \mathrm{H}_{4}\right)\right] \mathrm{Cl}_{2}$} & 19 \\
\hline 5 & $\mathrm{~K}_{2}\left[\mathrm{Co}_{2}\left(\mathrm{~L}_{2}\right)\right]$ & 18 \\
\hline 6 & {$\left[\mathrm{Co}\left(\mathrm{L}_{2} \mathrm{H}_{4}\right)\right]\left(\mathrm{NO}_{3}\right)_{2}$} & 21 \\
\hline Vancomycin & $\mathrm{Control}$ & 18 \\
\hline Ligand & $\mathrm{L}_{3} \mathrm{H}_{4}$ & 7 \\
\hline 7 & {$\left[\mathrm{Co}\left(\mathrm{L}_{3} \mathrm{H}_{4}\right)\right] \mathrm{Cl}_{2}$} & 16 \\
\hline 8 & $\mathrm{~K}_{2}\left[\mathrm{Co}\left(\mathrm{L}_{3}\right)\right]$ & 14 \\
\hline 9 & {$\left[\mathrm{Co}\left(\mathrm{L}_{3} \mathrm{H}_{4}\right)\right]\left(\mathrm{NO}_{3}\right)_{2}$} & 10 \\
\hline Vancomycin & $\mathrm{Control}$ & 15 \\
\hline
\end{tabular}

• قطر دائرة التثبيط مطروح منه قطر القرص. 
تحديد التركيز الادنى المثبط (MIC): نم تحديد التركيز الأدنى المثبط لبعض المعقدات التي أبرزت وأعطت قدرة تثبيطية جيدة من خلال تحضير المحاليل المخففة بالثراكيز الآثية (200 و 100 و 50 و 25 و 12.5) ملغم/ مل من كل معقد وحدد التركيز الأدنى المثبط وهو أعلى تخفيف يمنع نمو الجراثيم وكما هو مبين في (الجدول 5)، فضلاً عن ذلك تم تحديد قطر المنطقة المثبطة للمعقدات التي أخذت لها التراكيز المخففة ضد نمو البكتريا وقد لوحظ انه بزيادة تركيز المادة المستخدمة يزداد قطر المنطقة الخالية من النمو البكتيري وكما هو موضح في النتائج التي حصلنا عليها والتي بينها (الجدول 6) وأكدتها الصورة المرفقة (3)، إذ تشير لتهدير الأرقام (1 و 2 و 3 و4 و 5) في الصور إلى التراكيز المختلفة ابتداء من أعلى تركيز إلى اقل تركيز وحسب الترتيب الأتي: (200 و 100 و 50 و 25 و 2.5 و و 12.5 على التوالي.

الجدول 5: مستوى التراكيز الدنيا المثبطة (MIC) ملفم/مل

\begin{tabular}{|c|c|c|}
\hline Comp. No. & Compound & S. aureus \\
\hline 1 & {$\left[\mathrm{Co}\left(\mathrm{L}_{1} \mathrm{H}_{4}\right)\right] \mathrm{Cl}_{2}$} & 25 \\
\hline 2 & $\mathrm{~K}_{2}\left[\mathrm{Co}\left(\mathrm{L}_{1}\right)\right]$ & 12.5 \\
\hline 5 & $\mathrm{~K}_{2}\left[\mathrm{Co}\left(\mathrm{L}_{2}\right)\right]$ & 50 \\
\hline 6 & {$\left[\mathrm{Co}\left(\mathrm{L}_{2} \mathrm{H}_{4}\right)\right]\left(\mathrm{NO}_{3}\right)_{2}$} & 50 \\
\hline 7 & {$\left[\mathrm{Co}\left(\mathrm{L}_{3} \mathrm{H}_{4}\right)\right] \mathrm{Cl}_{2}$} & 25 \\
\hline 8 & $\mathrm{~K}_{2}\left[\mathrm{Co}\left(\mathrm{L}_{3}\right)\right]$ & 25 \\
\hline
\end{tabular}

الجدول 6: تأثير المعقدات على البكتريا الموجبة لصبغة كرام S. aureus باستخدام تراكيز مختلفة

\begin{tabular}{|c|c|c|c|c|c|c|}
\hline \multirow{2}{*}{$\begin{array}{c}\text { Comp. } \\
\text { No. }\end{array}$} & \multirow{2}{*}{ Compound } & \multicolumn{5}{|c|}{ Conc. of complex No. (mg/ml) } \\
\cline { 3 - 7 } & & $\mathbf{2 0 0}$ & $\mathbf{1 0 0}$ & $\mathbf{5 0}$ & $\mathbf{2 5}$ & $\mathbf{1 2 . 5}$ \\
\hline 1 & {$\left[\mathrm{Co}\left(\mathrm{L}_{1} \mathrm{H}_{4}\right)\right] \mathrm{Cl}_{2}$} & 21 & 17 & 13 & 10 & 4 \\
\hline 2 & $\mathrm{~K}_{2}\left[\mathrm{Co}\left(\mathrm{L}_{1}\right)\right]$ & 22 & 20 & 15 & 10 & 8 \\
\hline 5 & $\mathrm{~K}_{2}\left[\mathrm{Co}\left(\mathrm{L}_{2}\right)\right]$ & 15 & 15 & 10 & 2 & 2 \\
\hline 6 & {$\left[\mathrm{Co}\left(\mathrm{L}_{2} \mathrm{H}_{4}\right)\right]\left(\mathrm{NO}_{3}\right)_{2}$} & 21 & 19 & 15 & 9 & 4 \\
\hline 7 & {$\left[\mathrm{Co}\left(\mathrm{L}_{3} \mathrm{H}_{4}\right)\right] \mathrm{Cl}_{2}$} & 21 & 21 & 16 & 8 & 3 \\
\hline 8 & $\mathrm{~K}_{2}\left[\mathrm{Co}\left(\mathrm{L}_{3}\right)\right]$ & 14 & 12 & 7 & 5 & 1 \\
\hline
\end{tabular}

نتائج تقدير كمية البروتين: تم تقدير البروتين الكلي بطريقة لاوري كما ذكر سابقا من المواد وطرائق العمل لجرثومة Staph. aureus قبل وبعد معاملتها بالمعقدات المحضرة والتي أدت إلى تثبيط نموها وبأقل التراكيز (MIC) كما سبق ذكره في (الجدول 6). أوضح (الجدول 7) التغيير في كمية البروتين الكلي لجرثومة Staph. aureus بعد معاملتها بالمعقدات المحضرة. اذ تنين أن المعقدين

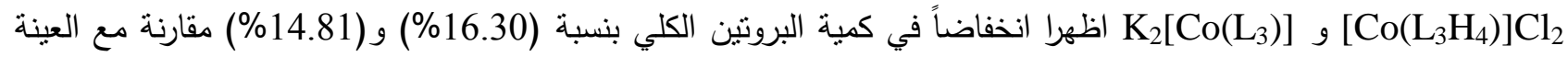
غير المعاملة لجرثومة Staph. aureus ان استخدام المعقدين قد أثز على مسار البروتين فيؤدي إلى تثنيطه وبالتالي نقصان

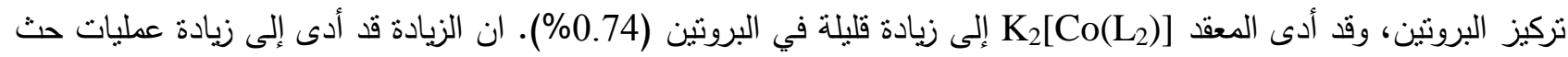
بناء البروتين اما بالنسبة للمعقدات

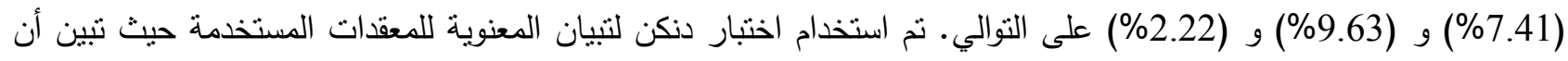
هنالك فرق غير معنوي وكما وضحته الأحرف المتشابهة عند المقارنة بين الجرثومة الغير معاملة مع الجرثومة المعاملة بالمعقدات 
الجدول 7: كمية البروتين بالمايكروغرام/ملغم وزن جاف لجرثومة Staphylococcus aureus المعاملة بالمعقدات المحضرة

\begin{tabular}{|c|c|c|c|c|}
\hline النسبة المئوية للتغيير & النسبة المئوية للكمية & المعنوية & المعدل ـ الخطأ البروتين القياسي & المعاملة \\
\hline- & 100 & $\mathrm{a}$ & $1.34 \pm 16.88$ & الجرثومة غير المعاملة \\
\hline-7.41 & 92.59 & $\mathrm{a}$ & $0.55 \pm 15.63$ & {$\left[\mathrm{Co}\left(\mathrm{L}_{1} \mathrm{H}_{4}\right)\right] \mathrm{Cl}_{2}$} \\
\hline-9.63 & 90.37 & $\bar{a}$ & $0.92 \pm 15.25$ & $\mathrm{~K}_{2}\left[\mathrm{Co}\left(\mathrm{L}_{1}\right)\right]$ \\
\hline-2.22 & 97.78 & $\mathrm{a}$ & $1.77 \pm 16.50$ & {$\left[\mathrm{Co}\left(\mathrm{L}_{2} \mathrm{H}_{4}\right)\right]\left(\mathrm{NO}_{3}\right)_{2}$} \\
\hline+0.74 & 100.74 & $\mathrm{a}$ & $0.50 \pm 17.00$ & $\mathrm{~K}_{2}\left[\mathrm{Co}\left(\mathrm{L}_{2}\right)\right]$ \\
\hline-16.30 & 83.70 & $\mathrm{a}$ & $0.31 \pm 14.13$ & {$\left[\mathrm{Co}\left(\mathrm{L}_{3} \mathrm{H}_{4}\right)\right] \mathrm{Cl}_{2}$} \\
\hline-14.81 & 85.19 & $\mathrm{a}$ & $1.09 \pm 14.38$ & $\mathrm{~K}_{2}\left[\mathrm{Co}\left(\mathrm{L}_{3}\right)\right]$ \\
\hline
\end{tabular}

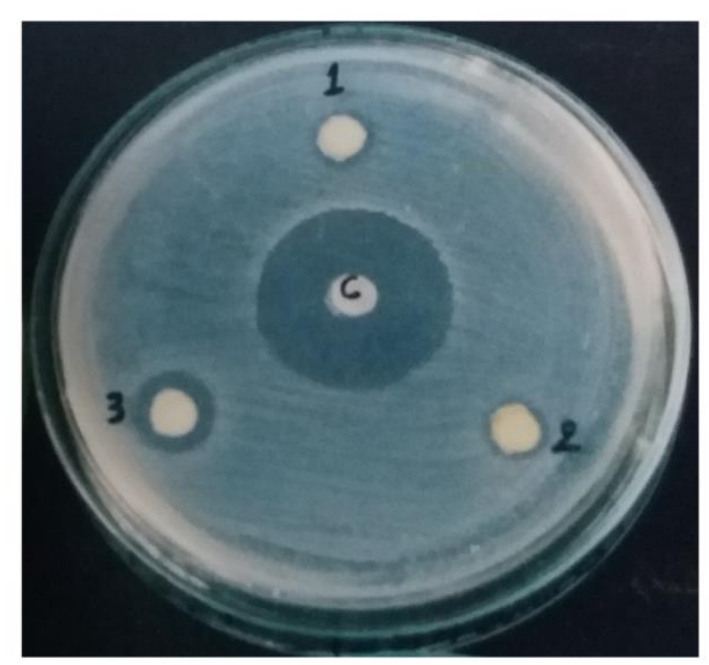

S. aureus صورة (1) تأثير الليكاندات على بكتريا

رقم (1) يشير الى الليكاند L L 
صهباء علي احمد وآخرون

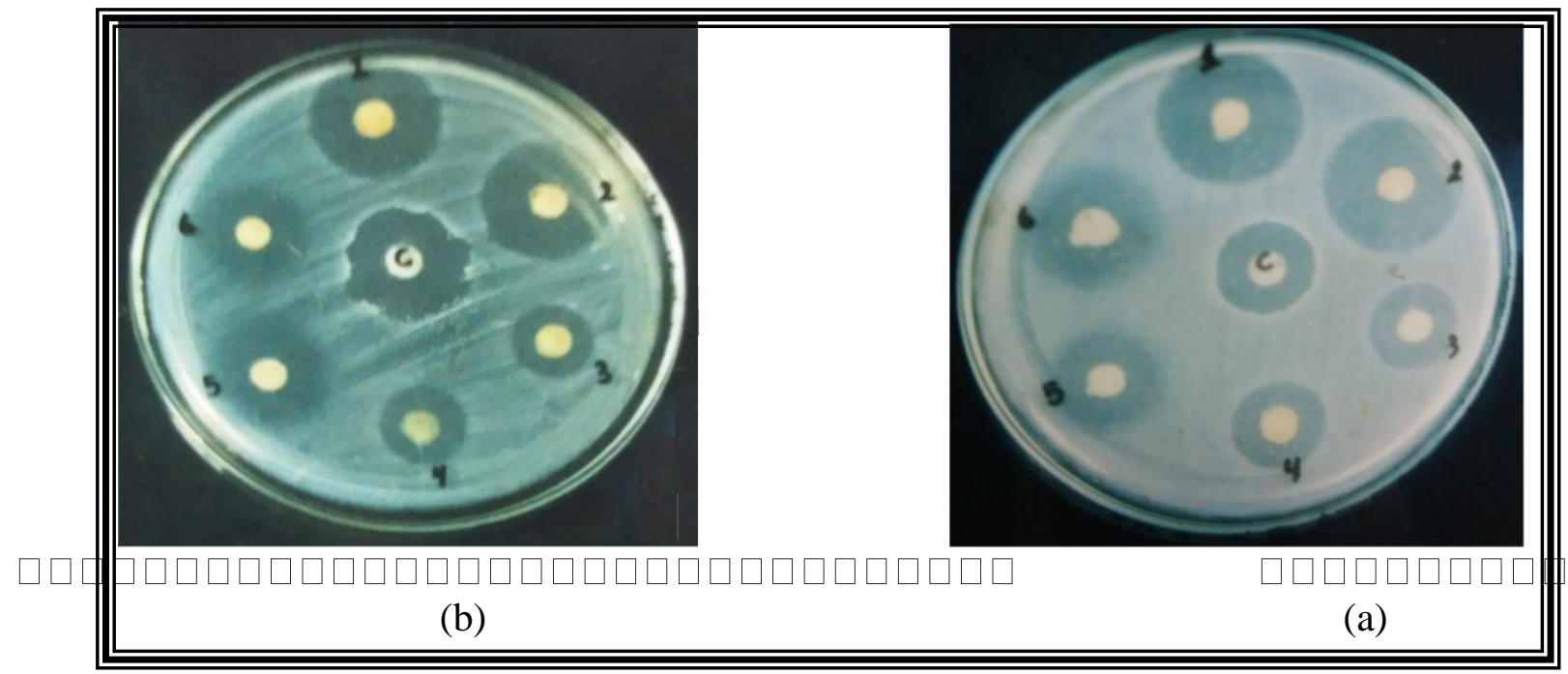

الصورة 2: تأثير معقدات الوسط المتعادل لليكاندات على بكتريا S aureus اذ تثير الأرقام (1، 2، 3، 4، 5، 6) الى

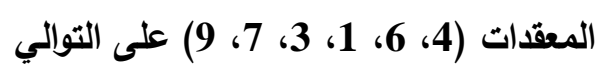

(a) تأثير معقدات الوسط القاعدي لليكاندات على بكتريا S. aureus اذ تثير الارقام (1، 2، 3، 4، 5، 6) الى المعقدات

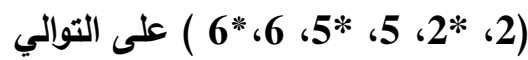

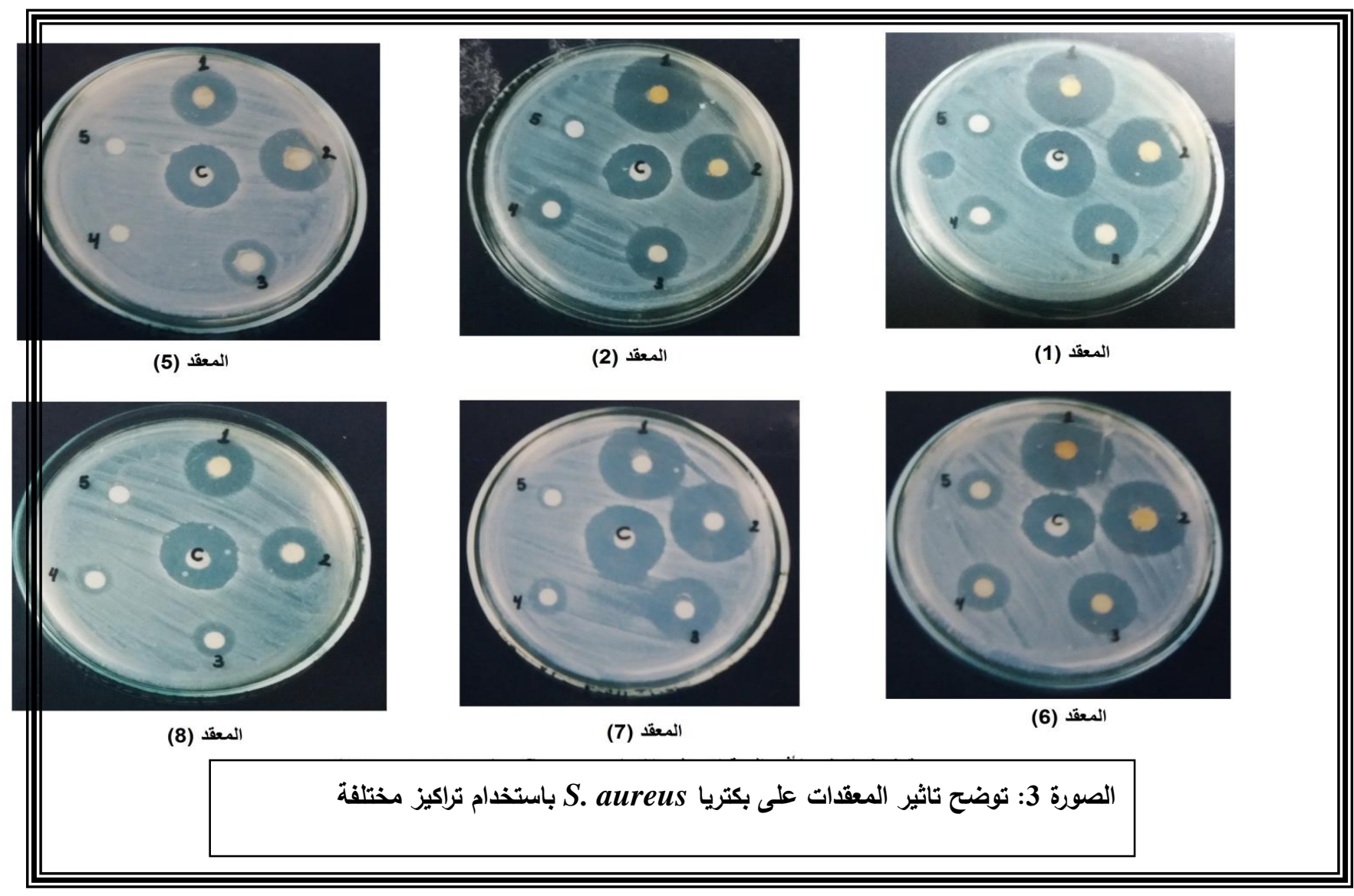




\section{الاستتتاجات}

نستتتج من الدراسات المختلفة الفيزيائية والكيميائية والطيفية التي اجريت على المعقدات الناتجة عن تفاعلات الليكاندات مع الاتع الأملاح الفلزية المختلفة أن الليكاندات الثلاثة المحضرة في بحثنا هذا ترتبط بطريقتنين مختلفتين:

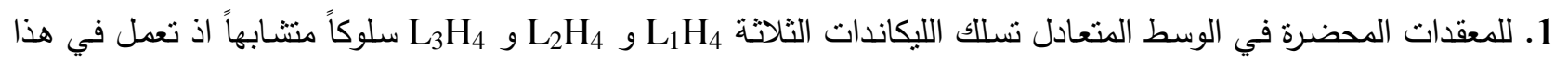
الوسط بشكل ليكاندات متعادلة سداسية السن لنتكون معقدات تكون فيها الذرة الفلزية سداسية التتاسق، لذلك تكون للمعقدات بنية ثماني السطوح وكما هو مبين في الثكل (1).

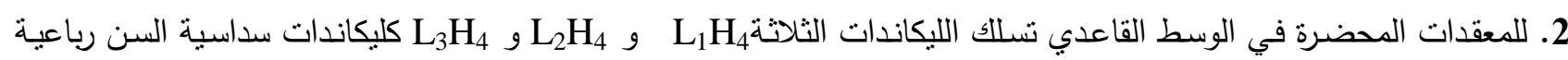

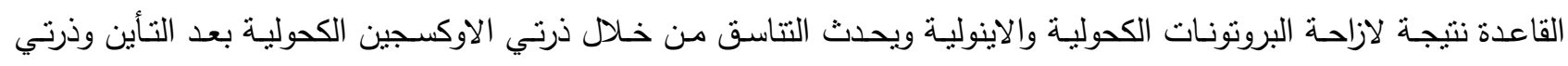
الاوكسجين الاينولية وذرتي النتروجين لمجموعتي الازوميثان لتنكون معقدات سداسية النتاسق لها بنية ثماني السطوح، وكما هو

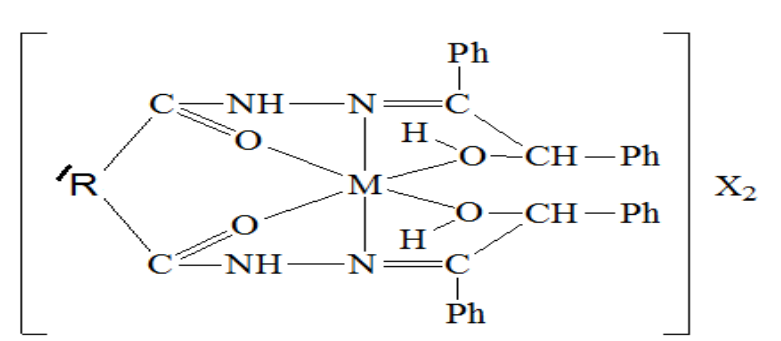

[Co $\left.\left(\mathrm{LH}_{4}\right)\right] \mathrm{X}_{2}$

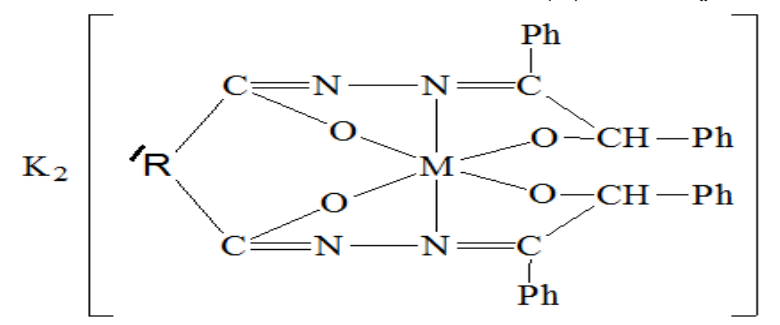

$\mathrm{K}_{2}[\mathrm{Co}(\mathrm{L})]$

$$
\mathrm{X}=\mathrm{Cl}^{-}, \mathrm{NO}_{3}^{-} \mathrm{L}=\mathrm{L}_{1}, \mathrm{~L}_{2}, \mathrm{~L}_{3}
$$

$\mathrm{R}=\mathrm{CH}_{2}, \mathrm{CH}_{2}-\mathrm{CH}_{2}$, ph

شكل (1)

شكل (2)

3. من الدراسة البايولوجية لليكاندات ومعقداتها المحضرة في الوسطين المتعادل والقاعدي استتنجنا أن لهذه المركبات فعالية تثبيطية ضد نمو البكتربا المستعملة الموجبة لصبغة كرام، إذ لوحظ أن للمعقدات المحضرة فعالية أكثر من الليكاندات مما يدل فلئل

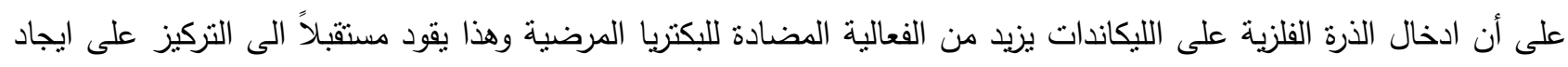

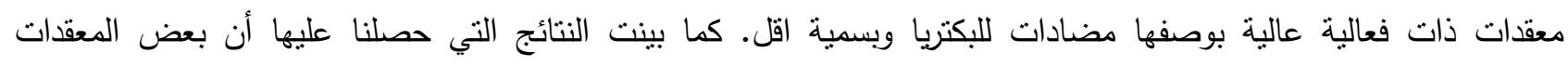
المحضرة قد أعطت فعالية أعلى من فعالية المضاد الحيوي المستخدم كما لوحظ وجود تفاوت في فعالية هذه المركبات في تثبيط

$$
\text { نمو البكتريا. }
$$

4. حدد التركيز الادنى المثبط (MIC) لبعض المعقدات المحضرة والتي أظهرت فعالية عالية في تثبيط نمو البكتريا المرضية وقد دلت النتائج على وجود تأثثر لبعض المعقدات على طبيعة البروتينات الكلية للجرثومة قيد الدراسة بنسب متفاوتة حيث أظهرت بعض منها نقصاناً في كمية البروتين في حين اظهر البعض الآخر زيادة في كمية البروتين.

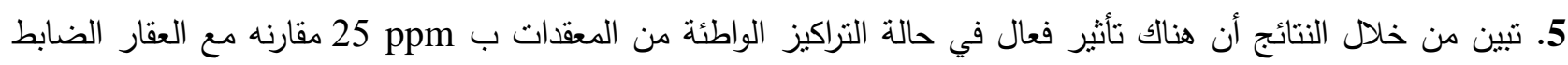
الليكندات تزداد فعاليتها عندما تتناسق مع املاح الايونات الفلزية وهذا السلوك للايون الفلزي في المعقد يعتمد على طبيعة التركيب

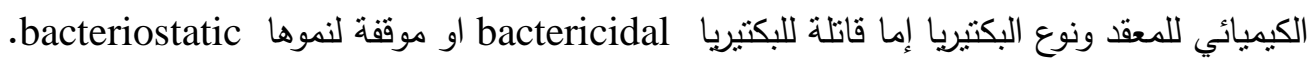

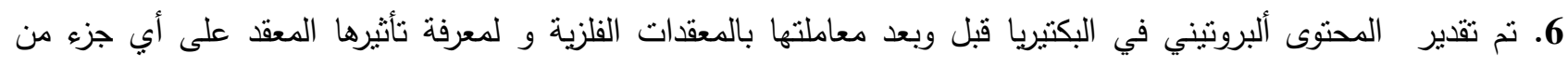
الأقسام الخلوية للبكتبريا حيث يمتص المعقد الفلزي عن طريق الجدار الخلوي ويترسب على السطح الداخلي للخلية ومن الدراسات 


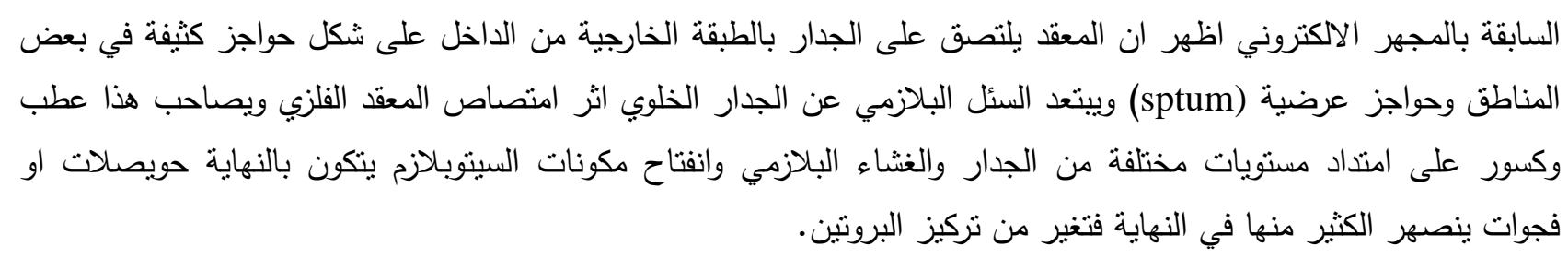

\section{المصادر}

Al-Shaheen, A.J.; Sallomi, I.J.; Al-Sabaawi, S.A. (2013). Some new Schiff Base Complexes of copper (II) and Their Biological Screening. Kirkuk Uni. J. Sci. Studies, 8(2), 48-58.

Alagesan, M.; Bhuvanesh, N.S.P.; Dharmaraj, N. (2013). Potentially cyotoxic new copper(II) hydrazone complexes: synthesis, crystal structure and biological properties. J. Chem. Soc., Dalton Trans., 42,7210 7223.

Al-Shaheen, A.J. (2011). Synthesis and fungitoxicity of copper(II) complexes. Raf. J. Sci., 2 Conference in chemistry 22-23 November, 374-388.

Al-Shaheen, A.J.; Sallomi, I.J.; Al-Sabaawi, S.A. (2012). Preparation, characterization of acid hyrazide Schiff Base complexes of nickel (II) and their biological activity. Iraqi National J. Chemistry, 48.

Al-Shaheen, A.J.; Al-Bayati, M.R.; Ali, A.M. (2017). Synthesis and characterization some of metal(II) complexes with 2-(6-methoxy naphthalene-2-yl) propionic acid (2-hydroxy benzylidene) hydrazone. International J. Enhenced-Resear., Technol. and Engm., ISSN: 2319-7463, 6(11).

Baker, W.; Haksar, C.N.; Mcomie, F.W. (1950). Fluorescent reagents. acyl chlorides and acyl hydrazides. J. Chem. Soc., 170.

Bauer, A.W.; Kirby, W.A.M.; Sherris, J.S.; Turk, M. (1966). Antibiotic susceptibility testing by a standardized single disk method. Am. J. Clin. Pathol., 45, 493-496.

Bavin, E.M.; Drain, D.J.; Seilerr, M.; Seymour, D.E. (1952). Some new metal complexes as possible bactericide. Pharm and Pharmacol., 4, 844.

Bernhardt, P.V.; Wilson, G.J.; Sharpe, P.C.; Kalinowski, D.S.; Richardson, D.R. (2008). Tuning the antiproliferative activity of biologically active iron chelators: characterization of the coordination chemistry of 2-acetylpyridine and 2-benzoylpyridine hydrazone ligands. $J$. Biol. Inorg. Chem., 13, 107-119.

Chohan, Z.H.; Farooq, M.A.; Iqbal, M.S. (2000). Synthesis, characterization and biological properties of anions on bivalent transition metal Co (II) and $\mathrm{Ni}$ (II) complexes with acylhydrazine-derived ONO donor Schiff bases. Metal-Based Drugs., 7, 133-139.

Figgs, B.N.; Lewis, J. (1960). "Modern Coordination Chemistry". Inter science, New York, 400 p.

Laurence, D.R.; Bennette, P.N. (1990). "Clinical Pharmacology". 6 ${ }^{\text {th }}$ ed., English Language Book Society, pp. 193-197.

Lever, A.B.P. (1968). Electronic spectra of some transition metal complexes. J. Chem. Edu., 45(11), 711.

Lowry, O.H.; Rosebrough, N.J.; Farr A.L.; Randall, R.J. (1951). Protein measurement with the follinphenol reagent. J. Biol. Chem., 193, 265-275

Manoussakis, G.; Bolos, C.; Ecateriniadou, L.; Sarris, C. (1987). Synthesis, characterization and anti-bacterial studies of mixed-ligand complexes of dithiocarbamato-thiocyanato and iron (III), nickel (II), copper (II) and zinc (II). Eur. J. Med. Chem., 22, 421-425.

Marshall, A.J.H.; Piddock, L.J.V. (1993). Effect of cations and EDTA upon the activity 18 quinolones, gentamicin, ceftazidin and polymixin against Gram-negative and Gram-positive bacteria. Drugs, 45(3), 150-151. 
Muhi-Eldeen, Z.; Nadir, M.; Al-Jobori, N.R.; Hussein, F.; Jstohs, S. (1991). Synthesis and study of transition metal compounds with expected biological activity. Eur. J. Med. Chem., 26, 237.

Nakamoto, K. (1978). "Infrared and Raman Spectra of Inorganic and Coordination Compound". $3^{\text {rd }}$ ed., John Wiley and Sons, New York, pp. 322, 244, 166, 173, 187.

Nawas, T.E.; Mawajden, S.; Dabned, A.; Al-Omari, A. (1994). Vitro activities of antimicrobial agents against proteusspp. Clinical Speciments. Br. J. Biomed Sci., 51(20), 95-99.

Novak, F.R.; Dasilva, A.V.; Hagler, A.N.; Figueiredo, A.M.S. (2000). Contamination of expressed human breast milk with an epidemic, multiresistant Staphylococcus aureus clone. J. Med. Microbiol., 49, 1109-1117.

Prescott, L.M.; Harley, J.P. (1996). "Laboratory Exercises in Microbiology". $3^{\text {rd }}$ ed., WCB McGraw-Hill, Iowa, USA.

Prescott, L.M.; Harley, J.P.; Klein, D.A. (1996). " Microbiology". $3^{\text {rd }}$ ed., Wm. C. Brown Publisher, London, Chicago, pp. 436-450.

Rai, H.C.; Sharma, R.U.; Thakur, R.S. (1986). Complexes of copper (II), nickel (II) and cobalt (II) with bis (1,2-diphenyl-1-hydroxyimino-2-ethylidine)-1,2-diaminobenzene. J. Indian Chem. Soc., 63, 495.

Richards, R.M.E.; Xing, J.Z.; Gregory, D.W.; Marshall, D. (1993). An electron-microscope study of the effect of sulphadiazine and trimethoprim on Enterobacter cloaca. J. Med. Microbiol., 38, 64-68.

Sallomi, I.J.; Al-Shaheen, A.J. (1994). Complexes of hydrazide Schiff bases. Transition, Met. Chem., 19, 275.

Sallomi, I.J.; Hadad, R.A.E. (2004). Study of the preparation and biological activity of cobalt (II) and nickel (II) complexes. J. Edu. Sci., 16(2), 110-124.

Sallomi, I.J.; Al-Shaheen, A.J.; Al-Sabaawi, S.A. (2011). Acid hydrazide Schiff base complexes of cobalt (II) and their biological activity. Raf. J. Sci., 2, sci-Conference in chemistry, 22-23 November, 389-400.

Sallomi, I.J. (2003). Synthesis and physicochemical studies of some cobalt (II), nickel (II) and copper macrocylic complexes. J. Edu. Sci., 15(2), 60-66.

Sallomi, I.J.; Al-Sabaawi, S.A. (2001). Complexes of cobalt, nickel and copper with acetylacetone derivatives. J. Edu. Sci., 51, 96-100.

Sankar, R.; Vijaylakshmi, S.; Rajagopan, S.; kahyapan, T. (2010). Synthesis, spectral, thermal and chelation potential of polymertic hydrazon based on 2,4-dihydroxy benzophenone. J. Appl. Polym. Sci., 117, 2146-2152

Sathyadevi, P.; Krishnamoorthy, P.; Algesan, M.; Thanigaimani, K.; Muthiah, P.T.; Dharmaraj, N. (2012). Synthesis crystal structure, electrochemistry and studies on protein binding, antioxidant and biocidal activities of $\mathrm{Ni}(\mathrm{II})$ and $\mathrm{Co}(\mathrm{II})$ hydrazone complexes. Polyhedron, 31, 294-306.

Savanini, L.; Chiasserini, L.; Gaeta, A.; Peiierano, C. (2002). Synthesis, antitubercular, evaluation of 4-quinolyhydrazoncs. Bioorg. Med. Chem., 10, 2193-2199

Schraufstatter, E. (1950). Formation of heavy-metal complexes and antibacterial. Z. Naturforsch, 5B, 190; Chem. Abstr., (1955), 44, 8999g.

Vandepitte, J.; Engback, K.; Pito, P.; Heuk, G. (1991). "Basic Laboratory Procedure in Clinical Bacteriology". World Health Organization, Geneva, pp. 78-85.

Vogel, A.I. (1971). "A Text Book of Quantitative Inorganic Chemistry". $3^{\text {rd }}$ ed., John Wiley, pp. $479,497,529$. 